\title{
Treatment costs of cystoid macular edema among patients following cataract surgery
}

\author{
This article was published in the following Dove Press journal: \\ Clinical Ophthalmology \\ 16 March 2016 \\ Number of times this article has been viewed
}

\author{
Jordana K Schmier \\ David W Covert ${ }^{2}$ \\ Carolyn K Hulme-Lowe' \\ Anmol Mullins ${ }^{3}$ \\ Emmanuel M Mahlis ${ }^{4}$ \\ 'Health Sciences, Exponent Inc., \\ Alexandria, VA, ${ }^{2}$ Health Economics, \\ ${ }^{3}$ Global Market Access, ${ }^{4}$ US Pharma \\ Medical Affairs, Alcon Inc., Fort Worth, \\ TX, USA
}

Purpose: The current costs of treating cystoid macular edema (CME), a complication that can follow cataract surgery, are largely unknown. This analysis estimates the treatment costs for CME based on the recently released US Medicare data.

Setting: Nationally representative database.

Design: Retrospective analysis of the 2011 through 2013 Medicare 5\% Beneficiary Encrypted Files.

Methods: Beneficiaries who underwent cataract surgery were identified and stratified by diagnosis of CME (cases) or no diagnosis of CME (controls) within 6 months following surgery. Claims and reimbursements for ophthalmic care were identified. Subgroup analyses explored the rates of CME in beneficiaries based on the presence of selected comorbidities and by the type of procedure (standard vs complex). Total Medicare and ophthalmic costs for cases and controls are presented. The analysis explored the effect of considering diabetic macular edema (DME) and macular edema (ME) as exclusion criteria.

Results: Of 78,949 beneficiaries with cataract surgery, $2.54 \%(n=2,003)$ were diagnosed with CME. One-third of beneficiaries had one or more conditions affecting retinal health (including diabetes), $4.5 \%$ of whom developed CME. The rate of CME, at $22.5 \%$, was much higher for those patients with preoperative DME or ME. Ophthalmic charges were almost twice as high for cases compared with controls (US\$10,410 vs $\$ 5,950)$; payments averaged $85 \%$ higher $(\$ 2,720$ vs $\$ 1,470$ ) (both $P<0.0001$ ).

Conclusion: Substantial costs can be associated with CME; beneficiaries whose retinas are already compromised before cataract surgery face higher risk. Cost savings could be realized with the use of therapies that reduce the risk of developing CME. Future analyses could identify whether and to what extent comorbidities influence costs.

Keywords: claims analysis, costs and cost analysis, cystoid macular edema, diabetic retinopathy

\section{Introduction}

Cataract is a leading cause of visual impairment in the US, with almost one-third of adults aged 65 years and older having been diagnosed with the condition. ${ }^{1}$ It is the most common cause of low vision among adults older than 40 years. ${ }^{2}$ More than 20 million Americans have cataracts in one or both eyes, ${ }^{2}$ and prevalence increases with age. ${ }^{3}$ Among Medicare beneficiaries, 20\% had a claim for cataract diagnosis between 1981 and 1988; cataracts were responsible for more than half of all allowable charges for eye care in the 1980s. ${ }^{4}$ This continued to be the main source of Medicare ophthalmic charges in the 1990 s. ${ }^{5}$ Despite the expense of the surgery, cataract surgery has consistently been demonstrated to be cost-effective, with recent analyses reiterating this finding given trends in disease and treatment strategies. ${ }^{6,7}$
Correspondence: Jordana K Schmier Exponent Inc., I 800 Diagonal Road, Suite 500, Alexandria, VA 223I4, USA $\mathrm{Tel}+\mid$ 57| 227724 I

Fax + I 57I 2277299

Email jschmier@exponent.com (c) (1) (5) ( 2016 Schmier et al. This work is published and licensed by Dove Medical Press Limited. The full terms of this license are available at https://www.dovepress.com/terms.php (c) hereby accept the Terms. Non-commercial uses of the work are permitted without any further permission from Dove Medical Press Limited, provided the work is properly attributed. For permission for commercial use of this work, please see paragraphs 4.2 and 5 of our Terms (https://www.dovepress.com/terms.php). 
Visual impairment can affect health-related quality of life and functioning, ${ }^{8,9}$ and cataract extraction has been shown to significantly improve the quality of life..$^{10,11}$ However, there are risks associated with cataract extraction. Cystoid macular edema (CME) may present after cataract surgery. Clinically significant $\mathrm{CME}$ is a pervasive condition that has been studied extensively. It is a primary leading reason for visual impairment following cataract extraction and, if left untreated, may result in retinal changes and irreversible vision loss. ${ }^{12}$ Patients who develop CME experience blurriness or visual distortion, may exhibit photosensitivity, and may have dim or pink-tinted vision. Although acute cases of CME may resolve within 4 months or even more quickly with the use of nonsteroidal anti-inflammatory drugs (NSAIDs), ${ }^{13}$ for patients with certain comorbidities, particularly diabetes or uveitis, CME may take up to 12 months to return to pre-CME vision. ${ }^{14,15}$ When CME fails to resolve with topical medical therapy, intravitreal injections of corticosteroids or antivascular endothelial growth factor and surgical treatments such as pars plana vitrectomy may be appropriate, but each therapy carries certain risks. ${ }^{16}$

Surprisingly, few studies have reported on the incidence of postcataract extraction CME. ${ }^{17}$ Published reports on the incidence of CME detected through clinical versus angiographic methods vary widely, which may be due to differences in diagnostic methods. Retinal tomography or ocular coherence tomography are occasionally used, but fluorescein angiography is generally considered to be the gold standard for CME diagnosis. Angiographic CME, which does not necessarily reduce visual acuity, occurs at much higher rates than clinically significant CME. ${ }^{18}$

In the Auckland Cataract Study, CME was reported in $3.8 \%$ of eyes within the month following surgery. ${ }^{19}$ Among cataract surgery patients with retinitis pigmentosa, $>14 \%$ of eyes had clinically confirmed cases of CME, while another $11 \%$ had suspected cases. ${ }^{20}$ Mentes et $\mathrm{al}^{21}$ reported that among a series of 252 patients, no eyes developed clinical CME and $9.1 \%$ developed angiographic CME within 45 days after uncomplicated phacoemulsification. In their study in 2012, Packer et $\mathrm{al}^{22}$ reported that of the 2,862 patients receiving phacoemulsification cataract extraction and intraocular lens implantation between 2007 and 2012, only three (0.1\%) were diagnosed with acute $\mathrm{CME}$ within 90 days of surgery. In contrast, among a group of 50 patients with nonproliferative diabetic retinopathy undergoing cataract surgery, almost onethird developed clinically significant macular edema (ME). ${ }^{23}$ Rossetti et $\mathrm{al}^{24}$ reported angiographic CME at 1 month following cataract surgery in a randomized, controlled trial among $2.4 \%$ of patients who received diclofenac eye drops compared to $17.4 \%$ of patients who received placebo.
CME and associated visual loss can cause anxiety for the patient and place additional demand on eye care services. This burden on the patient and health care system can be quantified and considered when estimating the costs of cataract surgery. Although the surgery is common in the US, few has been published on the costs resulting from the condition, with the exception of our previous work based on Medicare data from 1997 through 2001. ${ }^{25}$ The objective of this study is to quantify current costs associated with the treatment of CME in Medicare beneficiaries undergoing cataract surgery from 2011 to 2013 using recently released claims data and to identify beneficiaries at higher risk of developing CME.

\section{Methods}

Data were analyzed from the 2011 through 2013 Medicare Beneficiary Encrypted Files (BEF). The BEF represents a random 5\% sample of all Medicare enrollees and is representative of US citizens aged 65 years and older. The random sample used for this claims data set is selected based on the same algorithm each year. Thus, once selected, patients are included in the BEF data each year (until death) with new patients entering each year; therefore, longitudinal treatment patterns can be evaluated. The BEF data consist of seven claims components: inpatient, outpatient, durable medical equipment, hospice, home health agency, skilled nursing facility (nursing home), and physician/supplier (Part B) claims. These claims data were obtained from the Centers for Medicare and Medicaid Services after the establishment of a data use agreement that sets standards for integrity, security, and confidentiality of the files and records. Use of these limited data sets does not require Privacy Board approval.

For this study, data from all beneficiaries with one or more claims for cataract surgery (CPT 66820-66984) were included. Patients were included if they had at least 3 months of data before the initial cataract surgery claim, 6 months of data after the initial surgery claim, and were eligible for Medicare due to age (at least 65 years) rather than disability. Beneficiaries were stratified into those who had a diagnosis of CME (International Classification of Diseases, Ninth Edition [ICD-9] 362.53) in the same quarter or the following quarter after surgery (cases) or those who did not have a CME diagnosis within this time period (controls). Beneficiaries who had a second cataract surgery within 6 months were excluded from the analysis.

Subgroup analyses compared beneficiaries with complex cataract surgery (CPT 66982) to those with standard cataract procedures. Another subgroup analysis examined beneficiaries with diabetic macular edema (DME) (ICD-9 362.07) and macular edema (ME) (ICD-9 362.83). 
Both claims (amounts billed to Medicare by medical professionals or institutions) and payments (amounts paid by Medicare) for the 6 months following cataract surgery were included in the analysis. To account for outliers, claims and payments were winsorized; values below the first percentile were set to the first percentile and those above the 99th percentile were set to the value of the 99th percentile. For ease of presentation, summary claim and payments measures were created: all inpatient, including hospice, skilled nursing facility, and inpatient records; all outpatient, including outpatient, durable medical equipment, home health agency, and Part $\mathrm{B}$ records; and all care, including all seven components of the Medicare files.

The analysis examined overall medical claims and payments as well as claims and payments related to ophthalmic care only. Claims and payments related to ophthalmic care were defined as being associated with ICD-9 diagnosis codes 360-379. In examining comorbid conditions, the analysis categorized anyone with a diagnosis of diabetic retinopathy during the observation period (ie, before or after cataract surgery) as having diabetes (ICD-9 diagnosis code 250). It is possible that patients with well controlled, noninsulindependent diabetes would not have any medical claims associated with this condition in the quarter before cataract surgery. Both unadjusted mean claims and payments are presented as well as adjusted differences (controlling for age, sex, and race) and 95\% confidence intervals.

For these analyses, costs were inflated to 2014. All data analysis was performed using SAS v9.4 (SAS Institute Inc., Cary, NC, USA).

\section{Results}

A total of 78,949 cataract surgery patients were identified who had 3 months of claims data and eligibility before surgery and 6 months afterward. Of these 2,003 (2.54\%) had a claim reported for $\mathrm{CME}$ within 6 months of the cataract surgery. Patients were fairly evenly distributed across age groups, whether they had complex or standard surgery, and across cases and controls (Table 1). Three-fifths of beneficiaries were female $(60.0 \%)$, and $87.1 \%$ were white. Interestingly, there was a lower proportion of women among complex procedure recipients (46.3\%) compared to standard procedures (61.1\%), and there were more white patients who received standard procedures (87.7\%) compared to complex surgery (79.2\%).

Among cataract surgery patients, a substantial number had comorbidities affecting retinal health in the quarter preceding cataract surgery (Table 2). The most common was diabetes, which was reported in $23.1 \%$ of cataract patients; the rate was similar between those who underwent complex
Table I Demographic characteristics by procedure type

\begin{tabular}{|c|c|c|c|}
\hline Characteristic & $\begin{array}{l}\text { Beneficiaries } \\
\text { with complex } \\
\text { surgery }\end{array}$ & $\begin{array}{l}\text { Beneficiaries } \\
\text { with standard } \\
\text { surgery }\end{array}$ & $\begin{array}{l}\text { All } \\
\text { beneficiaries }\end{array}$ \\
\hline $\mathrm{N}$ & 5,709 & 73,240 & 78,959 \\
\hline \multicolumn{4}{|c|}{ Age (frequency, \%) } \\
\hline $65-69$ years & 18.1 & 19.9 & 19.8 \\
\hline 70-74 years & 20.7 & 23.4 & 23.2 \\
\hline $75-79$ years & 21.6 & 23.5 & 23.4 \\
\hline 80-84 years & 20.2 & 19.4 & 19.4 \\
\hline$>84$ years & 19.4 & 13.8 & 14.2 \\
\hline Sex, female (\%) & 46.3 & 61.1 & 60.0 \\
\hline Race, white (\%) & 79.2 & 87.7 & 87.1 \\
\hline
\end{tabular}

versus standard surgery $(26.0 \%$ vs $23.1 \%)$. There were notable differences in the rates of diabetic retinopathy $(8.3 \%$ among cases, $3.7 \%$ among controls, and $3.9 \%$ overall) and among those with multiple conditions (14.0\% among cases, $2.5 \%$ among controls, and $2.8 \%$ overall). Beneficiaries with diabetes and diabetic retinopathy were not categorized as having multiple conditions but as having diabetic retinopathy only, for the purpose of this analysis.

As shown in Table 3, the rate of CME among patients with any comorbid retinal conditions was greater (range, 2.9\% among patients with diabetes with no diabetic retinopathy to $12.7 \%$ among those with multiple retinal conditions) than the rate among patients with no retinal comorbidities (1.5\%). In addition, the proportion of surgeries that were coded as complex versus standard was fairly similar across retinal comorbidities, ranging from $4.6 \%$ among those with epiretinal membrane to $9.0 \%$ among patients with diabetes (data not shown). Of note is that $6.6 \%$ of patients with no retinal comorbidities had complex cataract procedures, suggesting

Table 2 Comorbid retinal conditions before cataract surgery

\begin{tabular}{lll}
\hline Condition (ICD-9) & Cases & Controls \\
\hline $\mathrm{N}$ & 2.003 & 76,946 \\
Diabetes & $26.0 \%$ & $23.1 \%$ \\
Diabetic retinopathy & $8.3 \%$ & $3.7 \%$ \\
$\quad$ Background (362.0I) & $3.3 \%$ & $1.9 \%$ \\
Proliferative (362.02) & $1.4 \%$ & $0.6 \%$ \\
Nonproliferative (362.03) & $0.4 \%$ & $0.2 \%$ \\
Mild nonproliferative (362.04) & $0.7 \%$ & $0.3 \%$ \\
$\quad$ Moderate nonproliferative (362.05) & $0.4 \%$ & $0.1 \%$ \\
Severe nonproliferative (362.06) & $0.1 \%$ & $0.0 \%$ \\
$\quad$ Multiple diabetic retinopathy diagnoses & $1.9 \%$ & $0.6 \%$ \\
Epiretinal membrane & $8.4 \%$ & $3.6 \%$ \\
Retinal vein occlusion & $3.9 \%$ & $0.7 \%$ \\
Two or more conditions listed previously & $14.0 \%$ & $2.5 \%$ \\
None of the conditions listed previously & $39.3 \%$ & $66.3 \%$ \\
\hline
\end{tabular}

Notes: aAll patients with diabetic retinopathy were also assumed to have diabetes (even if it was not expressed in claims). This refers to other combinations of conditions.

Abbreviation: ICD-9, International Classification of Diseases, Ninth Edition. 
Table 3 Cases by comorbid retinal conditions

\begin{tabular}{llll}
\hline Condition (ICD-9) & \% cases: complex & \% cases: standard & \% cases: all \\
\hline $\mathrm{N}$ & 5,709 & 73,240 & 78,949 \\
Diabetes & 4.1 & 2.7 & 2.9 \\
Diabetic retinopathy & 5.3 & 5.5 & 5.5 \\
$\quad$ Background (362.0I) & 6.8 & 4.2 & 4.4 \\
$\quad$ Proliferative (362.02) & 0.0 & 6.4 & 5.7 \\
$\quad$ Nonproliferative (362.03) & 0.0 & 7.1 & 6.7 \\
$\quad$ Mild nonproliferative (362.04) & 4.5 & 5.0 & 5.0 \\
$\quad$ Moderate nonproliferative (362.05) & 0.0 & 7.5 & 7.0 \\
$\quad$ Severe nonproliferative (362.06) & 0.0 & 9.1 & 9.1 \\
$\quad$ Multiple diabetic retinopathy diagnoses & 10.7 & 7.9 & 7.9 \\
Epiretinal membrane & 10.9 & 5.5 & 5.7 \\
Retinal vein occlusion & 19.2 & 12.1 & 12.0 \\
Two or more conditions listed previously & 2.8 & 12.1 & 12.7 \\
None of the conditions listed previously & 1.4 & 1.5 \\
\hline Notes: & & \\
\hline
\end{tabular}

Notes: ${ }^{a}$ All patients with diabetic retinopathy were also assumed to have diabetes (even if it was not expressed in claims). This refers to other combinations of conditions. Abbreviation: ICD-9, International Classification of Diseases, ninth edition.

that the type of procedure performed may not be related to retinal comorbidities.

Table 4 presents case rates using alternative definitions for identifying the population and determining cases. The base case definitions are provided for reference. The first alternative presents rates for the same set of patients as the primary analysis, that is, that preprocedure DME or ME is not considered an exclusion criterion, but in this analysis, patients with diagnoses of DME or ME postprocedure are considered cases, in addition to the existing case definition of CME. The other two analyses present rates for a different population in which preprocedure DME or ME is considered an exclusion criterion. Again, postprocedure DME or ME is first considered a case, and then not included in the definition of a case. When emergent DME and ME diagnoses are considered cases, particularly among patients for whom there was no DME or ME before the cataract surgery, the rate of cases is more than twice as high for patients with diabetes (6.1\% vs $2.3 \%)$ and/or diabetic retinopathy (9.3\% vs $2.8 \%)$.
The rate of CME was $22.5 \%$ for those patients with preoperative DME or ME.

Tables 5 and 6 present claims and reimbursements for all care and ophthalmic care, respectively, by Medicare for patients during the 6 months following cataract surgery. In terms of overall medical claims (charges) and reimbursements (payments), there was one unusual finding, with payments for inpatient care significantly higher for controls than for cases $(\$ 2,100$ vs $\$ 1,600, P<0.05)$. Outpatient care claims and reimbursements were significantly higher for cases compared with controls, as were claims for total care $(\$ 27,340$ vs $\$ 22,790$ ) although the average 6 month reimbursement for all medical care was not significantly different between cases and controls.

Differences in claims and reimbursements for ophthalmic care were significant for outpatient care and overall, as shown in Table 6 (all at $P<0.001$ ). Claims were almost doubled for cases compared with controls $(\$ 10,410$ vs $\$ 5,950)$, and reimbursements were $\sim \$ 1,250$ higher (an $85 \%$ increase from

Table 4 Cases by comorbid retinal conditions: alternative definitions

\begin{tabular}{|c|c|c|c|c|}
\hline Definitions & Base case & Alternatives & & \\
\hline Preprocedure DME and ME & $\begin{array}{l}\text { Not exclusion } \\
\text { criterion } \\
\end{array}$ & $\begin{array}{l}\text { Not exclusion } \\
\text { criterion }\end{array}$ & $\begin{array}{l}\text { Exclusion } \\
\text { criterion } \\
\end{array}$ & $\begin{array}{l}\text { Exclusion } \\
\text { criterion }\end{array}$ \\
\hline Postprocedure DME and ME & Not case & Case & Case & Not case \\
\hline$N$ & 78,949 & 78,949 & 76,109 & 76,109 \\
\hline Diabetes & $2.9 \%$ & $7.8 \%$ & $6.1 \%$ & $2.3 \%$ \\
\hline Diabetic retinopathy & $5.5 \%$ & $22.7 \%$ & $9.3 \%$ & $2.8 \%$ \\
\hline Epiretinal membrane & $5.7 \%$ & $5.7 \%$ & $3.7 \%$ & $3.7 \%$ \\
\hline Retinal vein occlusion & $12.0 \%$ & $12.0 \%$ & $4.3 \%$ & $4.3 \%$ \\
\hline Two or more conditions listed previouslya & $12.7 \%$ & $33.8 \%$ & $16.5 \%$ & $6.8 \%$ \\
\hline None of the conditions listed previously & $1.5 \%$ & $1.5 \%$ & $1.3 \%$ & $1.8 \%$ \\
\hline
\end{tabular}

Notes: ${ }^{a} A l l$ patients with diabetic retinopathy were also assumed to have diabetes (even if it was not expressed in claims). This refers to other combinations of conditions. Abbreviations: DME, diabetic macular edema; ME, macular edema. 
Table 5 Medicare claims (charges) and reimbursements (payments) for cataract patients

\begin{tabular}{|c|c|c|c|c|c|c|}
\hline \multirow[t]{2}{*}{ Type } & \multicolumn{3}{|c|}{ Cases $(n=2,003)$} & \multicolumn{3}{|c|}{ Controls $(n=76,946)$} \\
\hline & $\%$ with claim & Avg claim/6 M & $\begin{array}{l}\text { Avg } \\
\text { reimbursement/6 M }\end{array}$ & $\%$ with claim & Avg claim/6 M & $\begin{array}{l}\text { Avg } \\
\text { reimbursement/6 M }\end{array}$ \\
\hline Inpatient care* & 9.0 & $\$ 5,540$ & $\$ 1,600$ & 0.0 & $\$ 6,820$ & $\$ 2,100$ \\
\hline Outpatient care** & 100.0 & $\$ 21,860$ & $\$ 5,410$ & 100.0 & $\$ 16,020$ & $\$ 4,020$ \\
\hline Total ${ }^{\mathrm{a}, * * *}$ & 100.0 & $\$ 27,340$ & $\$ 6,980$ & 100.0 & $\$ 22,790$ & $\$ 6,100$ \\
\hline
\end{tabular}

Notes: ${ }^{a}$ Totals may not equal the sums of inpatient and outpatient claims/payments due to averaging. $* P<0.05$, cases versus controls, for differences in payments. $* * P<0.00 \mathrm{I}$, cases versus controls, for differences in both claims and payments. $* * * P<0.05$, cases versus controls, for differences in claims. Currency is in USD as at 2014 .

Abbreviations: Avg, average; $M$, months.

$\$ 1,470$ to $\$ 2,720)$. There were very few inpatient encounters and no significant differences in claims or reimbursements.

\section{Discussion}

This study evaluated differences in rates of $\mathrm{CME}$ and costs for Medicare beneficiaries who developed CME within 6 months following cataract surgery compared with those who did not. Findings identified substantially higher costs (both claims and payments) associated with CME diagnosis and treatment compared to controls who did not develop the condition.

Whether patients affected with CME have similar clinical characteristics is unknown and somewhat conflicting results exist in the literature. It is possible that the type of lens or procedure may affect rates, consistent with Nikica et $\mathrm{al}^{26}$ finding that patients who received an anterior chamber lens or who experienced posterior capsule rupture or required anterior vitrectomy had higher rates of angiographic CME. Another study that reported on rates of angiographic CME following uncomplicated phacoemulsification found no significant differences in characteristics between cases and controls.

Specific comorbidities may be associated with risk of CME. Elevated blood pressure and cardiovascular disease were associated with the development of diffuse ME among patients with diabetic retinopathy. ${ }^{27}$ Henderson et al ${ }^{15}$ also found higher rates of postcataract surgery CME among patients with a history of retinal vein occlusion or diabetes; the postoperative prophylactic use of NSAIDs among these high-risk patients was associated with the rates of postoperative CME similar to those without increased risk. Similarly, this study found higher rates of pre-existing concomitant ophthalmic retinal conditions among cases, further suggesting that there may be greater risk of postsurgery CME among patients with histories of prior ophthalmic diseases. The increased risk of CME following cataract surgery among patients with diabetes has been shown in many other studies. ${ }^{15,28,29}$ In the current study, diabetic patients with pre-existing diabetic retinopathy had a 5.5\% rate of $\mathrm{CME}$ compared to a $1.5 \%$ rate of $\mathrm{CME}$ among patients with no pre-existing retinal comorbidities.

There are several limitations in this study. Since the Medicare claims data are primarily an administrative and billing database, clinical indicators (including whether disease is bilateral) and laboratory results are neither available for analysis nor is it possible to confirm that claims coded for CME were not simply "rule-out" diagnoses. As extensive documentation is not required for comorbid conditions, it is difficult to know the severity of diabetes in the population. As we have observed in other studies, rarely do claims code which eye was treated, requiring us to assume that the diagnosis of CME should be linked to a recent cataract surgery. This is likely but there could be other causes of CME. However, we would not expect nonsurgery-related $\mathrm{CME}$ to be more common in the cases compared to controls, so this limitation probably does not affect findings. Claims are only submitted when there is reimbursement to be requested, so suspected CME that is not documented, but might still be clinically relevant, cannot be identified. Despite the limitations of

Table 6 Ophthalmic Medicare claims (charges) and reimbursements (payments) for cataract patients - all beneficiaries

\begin{tabular}{|c|c|c|c|c|c|c|}
\hline \multirow[t]{2}{*}{ Type } & \multicolumn{3}{|c|}{ Cases $(n=2,003)$} & \multicolumn{3}{|c|}{ Controls $(n=76,946)$} \\
\hline & $\%$ with claim & Avg claim/6 M & $\begin{array}{l}\text { Avg } \\
\text { reimbursement/6 M }\end{array}$ & $\%$ with claim & Avg claim/6 M & $\begin{array}{l}\text { Avg } \\
\text { reimbursement/6 M }\end{array}$ \\
\hline Inpatient care & 11.0 & $\$ 0$ & $\$ 0$ & 0.0 & $\$ 10$ & $\$ 0$ \\
\hline Outpatient care* & 100.0 & $\$ 10,330$ & $\$ 2,710$ & 99.3 & $\$ 5,910$ & $\$ 1,470$ \\
\hline Totala ${ }^{\mathrm{a}, *}$ & 100.0 & $\$ 10,410$ & $\$ 2,720$ & 99.3 & $\$ 5,950$ & $\$ 1,470$ \\
\hline
\end{tabular}

Notes: ${ }^{a}$ Totals may not equal the sums of inpatient and outpatient claims/payments due to averaging. $* P<0.00$ I, for differences in both claims and payments. Currency is in USD as at 2014.

Abbreviations: Avg, average; M, months. 
administrative databases, the increased focus on Real-World Evidence rather than relying on clinical trials suggests that these databases, however, imperfect, can contribute substantially to the understanding of outcomes. ${ }^{30}$

CME and DME have many consequences that may not be captured in the direct medical costs identified in this analysis. The possibility of some visual impairment and decreased health-related quality of life is likely. Transient visual impairment might not necessitate rehabilitation, but it may increase the need for caregiver assistance, whether paid or unpaid, although these costs may be lower than others associated with long-term, progressive impairment. ${ }^{31-34}$ In patients with age-related macular degeneration, our previous work found that decreased visual acuity is associated with increased use of caregiver services and higher medical costs. ${ }^{35}$

Compared to our previous work, the relative and absolute cost of CME treatment is greater than before. ${ }^{25}$ Some of this increase may be due to different patterns of resource use among patients identified as cases, with more case patients in the 1997-2001 data having inpatient encounters $(22.6 \%$ vs $9.0 \%$ ) but fewer case patients in the previous analysis having ophthalmic inpatient encounters $(2.9 \%$ vs $11.0 \%)$. One notable difference in the studies is that the 1997-2001 analysis required 12 months of follow-up after cataract surgery; in the present analysis, only 6 months were required to maintain sample sizes. Particularly with this change, the increased rate of inpatient ophthalmic encounters for which an ophthalmic diagnosis was recorded seems remarkable, yet changes in practice patterns during the decade gap between the studies may account for some of this difference. Another likely cause of the higher cost of treating CME is the increased use of intravitreal injections, which have shown to be effective with few to no adverse events; however, more studies are needed to investigate this further. ${ }^{16,36-38}$

\section{Conclusion}

In summary, results from this analysis indicate that patients who are treated for CME following cataract surgery have higher Medicare claims and reimbursements than patients who do not develop CME. Prophylactic postoperative treatment for CME with anti-inflammatory agents could potentially decrease Medicare costs, which may be higher due to the increased use of intravitreal injections for the treatment of CME. The effectiveness of medical treatments such as topical NSAIDs for controlling inflammation (alone or in combination with a topical steroid) is well recognized. Singh et $\mathrm{al}^{39}$ found that among diabetic patients with pre-existing diabetic retinopathy, the use of an NSAID plus a steroid was associated with a significantly lower rate of $\mathrm{ME}$ versus steroid alone at days 30 and 90 (3.2\% vs $16.7 \%, P<0.001)$. A meta-analysis of randomized controlled trials published between 1966 and 1996 found that postoperative medical prophylaxis for aphakic and pseudophakic CME can be beneficial. ${ }^{40}$ Given the higher rates of CME among patients with pre-existing retinal disease, targeting interventions to these patients are likely to be cost-effective.

\section{Acknowledgment}

Funding for this research was provided by Alcon Inc.

\section{Disclosure}

No specific products are described in this manuscript. DWC, AM, and EMM are employees of Alcon Inc., which provided funding for the study. The authors report no other conflicts of interest in this work.

\section{References}

1. Klein R, Klein BE. The prevalence of age-related eye diseases and visual impairment in aging: current estimates. Invest Ophthalmol Vis Sci. 2013;54(14):ORSF5-ORSF13.

2. Congdon N, O'Colmain B, Klaver CC, et al. Causes and prevalence of visual impairment among adults in the United States. Arch Ophthalmol. 2004;122(4):477-485.

3. McGwin G, Khoury R, Cross J, Owsley C. Vision impairment and eye care utilization among Americans 50 and older. Curr Eye Res. 2010;35(6):451-458.

4. Ellwein LB, Urato CJ. Use of eye care and associated charges among the Medicare population: 1991-1998. Arch Ophthalmol. 2002;120(6): 804-811.

5. Salm M, Belsky D, Sloan FA. Trends in cost of major eye diseases to Medicare, 1991 to 2000. Am J Ophthalmol. 2006;142(6):976-982.

6. Lansingh VC, Carter MJ. Use of global visual acuity data in a time trade-off approach to calculate the cost utility of cataract surgery. Arch Ophthalmol. 2009;127(9):1183-1193.

7. Brown GC, Brown MM, Menezes A, Busbee BG, Lieske HB, Lieske PA. Cataract surgery cost utility revisited in 2012: a new economic paradigm. Ophthalmology. 2013;120(12):2367-2376.

8. Knudtson MD, Klein BE, Klein R, Cruickshanks KJ, Lee KE. Age-related eye disease, quality of life, and functional activity. Arch Ophthalmol. 2005;123(6):807-814.

9. Dev MK, Paudel N, Joshi ND, Shah DN, Subba S. Impact of visual impairment on vision-specific quality of life among older adults living in nursing home. Curr Eye Res. 2014;39(3):232-238.

10. Javitt JC, Steinert RF. Cataract extraction with multifocal intraocular lens implantation: a multinational clinical trial evaluating clinical, functional, and quality-of-life outcomes. Ophthalmology. 2000;107(11): 2040-2048,

11. Rosen PN, Kaplan RM, David K. Measuring outcomes of cataract surgery using the quality of well-being scale and VF-14 visual function index. J Cataract Refract Surg. 2005;31(2):369-378.

12. Tranos PG, Wickremasinghe SS, Stangos NT, Topouzis F, Tsinopoulos I, Pavesio CE. Macular edema. Surv Ophthalmol. 2004;49(5):470-490.

13. Sivaprasad S, Bunce C, Patel N. Non-steroidal anti-inflammatory agents for treating cystoid macular oedema following cataract surgery. Cochrane Database Syst Rev. 2005;1:CD004239.

14. Sivaprasad S, Bunce C, Wormald R. Non-steroidal anti-inflammatory agents for cystoid macular oedema following cataract surgery: a systematic review. Br J Ophthalmol. 2005;89(11):1420-1422. 
15. Henderson BA, Kim JY, Ament CS, Ferrufino-Ponce ZK, Grabowska A, Cremers SL. Clinical pseudophakic cystoid macular edema. Risk factors for development and duration after treatment. J Cataract Refract Surg. 2007;33(9):1550-1558.

16. Guo S, Patel S, Baumrind B, et al. Management of pseudophakic cystoid macular edema. Surv Ophthalmol. 2015;60(2):123-137.

17. Rossetti L, Autelitano A. Cystoid macular edema following cataract surgery. Curr Opin Ophthalmol. 2000;11(1):65-72.

18. Narayanan R, Kuppermann BD. Macular causes of poor postoperative vision: cystoid macular edema, epiretinal fibrosis, and age-related macular degeneration. In: Steinert RF, editor. Cataract Surgery. Elsevier Inc., Philadelphia, PA; 2010:661-669.

19. Riley AF, Malik TY, Grupcheva CN, Fisk MJ, Craig JP, McGhee CN. The Auckland cataract study: co-morbidity, surgical techniques, and clinical outcomes in a public hospital service. Br J Ophthalmol. 2002; 86(2):185-190.

20. Jackson H, Garway-Heath D, Rosen P, Bird AC, Tuft SJ. Outcome of cataract surgery in patients with retinitis pigmentosa. Br J Ophthalmol. 2001;85(8):936-938.

21. Mentes J, Erakgun T, Afrashi F, Kerci G. Incidence of cystoid macular edema after uncomplicated phacoemulsification. Ophthalmologica. 2003; 217(6):408-412

22. Packer M, Lowe J, Fine H. Incidence of acute postoperative cystoid macular edema in clinical practice. J Cataract Refract Surg. 2012; 38(12):2108-2111.

23. Krepler K, Biowski R, Schrey S, Jandrasits K, Wedrich A. Cataract surgery in patients with diabetic retinopathy: visual outcome, progression of diabetic retinopathy, and incidence of diabetic macular oedema. Graefes Arch Clin Exp Ophthalmol. 2002;240(9):735-738.

24. Rossetti L, Bujtar E, Castoldi D, Torrazza C, Orzalesi N. Effectiveness of diclofenac eyedrops in reducing inflammation and the incidence of cystoid macular edema after cataract surgery. J Cataract Refract Surg. 1996;22(suppl 1):794-799.

25. Schmier JK, Halpern MT, Covert DW, Matthews GP. Evaluation of costs for cystoid macular edema among patients after cataract surgery. Retina. 2007;27(5):621-628.

26. Nikica G, Ljerka HP, Jelena P, Metez-Soldo K, Mladen B. Cystoid macular edema in anterior chamber lens implantation following posterior capsule rupture. Doc Ophthalmol. 1992;81(3):309-315.

27. Lopes de Faria JM, Jalkh AE, Trempe CL, McMeel JW. Diabetic macular edema: risk factors and concomitants. Acta Ophthalmol Scand. 1999;77(2):170-175.
28. Lara-Smalling A, Cakiner-Egilmez T. Diabetes and cataract surgery: preoperative risk factors and positive nursing interventions. Insight. 2014;39(2):18-20.

29. Kim SJ, Equi R, Bressler NM. Analysis of macular edema after cataract surgery in patients with diabetes using optical coherence tomography. Ophthalmology. 2007;114(5):881-889.

30. Collier A [webpage on the Internet]. Filling the Black Hole: Can RealWorld Evidence Data Meet Demand? 2014. Available from: http:// www.pharmaphorum.com/articles/filling-the-black-hole-can-realworld-evidence-data-meet-demand. Accessed August 5, 2015.

31. Bonastre J, Le Pen C, Soubrane G, Quentel G. The burden of age-related macular degeneration: results of a cohort study in two French referral centres. Pharmacoeconomics. 2003;21(3):181-190.

32. Frick K, Basilion E, Hanson C, Colchero A. Estimating the burden and economic impact of trachomatous visual loss. Ophthalmic Epidemiol. 2003;10(2):121-132.

33. Frick KD, Gower EW, Kempen JH, Wolff JL. Economic impact of visual impairment and blindness in the United States. Arch Ophthalmol. 2007; 125(4):544-550.

34. Stenevi U, Lundstrom M, Thorburn W. The cost of cataract patients awaiting surgery. Acta Ophthalmol Scand. 2000;78(6):703-705.

35. Schmier JK, Halpern MT, Covert D, Delgado J, Sharma S. Impact of visual impairment on use of caregiving by individuals with age-related macular degeneration. Retina. 2006;26(9):1056-1062.

36. Spitzer MS, Ziemssen F, Yoeruek E, Petermeier K, Aisenbrey S, Szurman P. Efficacy of intravitreal bevacizumab in treating postoperative pseudophakic cystoid macular edema. J Cataract Refract Surg. 2008; 34(1):70-75

37. Mitropoulos PG, Chatziralli IP, Peponis VG, Drakos E, Parikakis EA. Intravitreal ranibizumab for the treatment of Irvine-Gass syndrome. Ocul Immunol Inflamm. 2015;23(3):225-231.

38. Arevalo JF, Maia M, Garcia-Amaris RA, et al. Intravitreal bevacizumab for refractory pseudophakic cystoid macular edema: the Pan-American Collaborative Retina Study Group results. Ophthalmology. 2009;116(8): 1481-1487, 1487e1481.

39. Singh R, Alpern L, Jaffe GJ, et al. Evaluation of nepafenac in prevention of macular edema following cataract surgery in patients with diabetic retinopathy. Clin Ophthalmol. 2012;6:1259-1269.

40. Rossetti L, Chaudhuri J, Dickersin K. Medical prophylaxis and treatment of cystoid macular edema after cataract surgery. The results of a meta-analysis. Ophthalmology. 1998;105(3):397-405.
Clinical Ophthalmology

\section{Publish your work in this journal}

Clinical Ophthalmology is an international, peer-reviewed journal covering all subspecialties within ophthalmology. Key topics include: Optometry; Visual science; Pharmacology and drug therapy in eye diseases; Basic Sciences; Primary and Secondary eye care; Patient Safety and Quality of Care Improvements. This journal is indexed on Submit your manuscript here: http://www.dovepress.com/clinical-ophthalmology-journal

\section{Dovepress}

PubMed Central and CAS, and is the official journal of The Society of Clinical Ophthalmology (SCO). The manuscript management system is completely online and includes a very quick and fair peer-review system, which is all easy to use. Visit http://www.dovepress.com/ testimonials.php to read real quotes from published authors. 